\title{
Numerical Simulation Study of Wellbore Temperature Distribution of Binary Compound Flooding Injection Well
}

\author{
Gou Feifei ${ }^{1,2}$, Liu weidong ${ }^{2,3}$, Zhang Feifei ${ }^{4}$ \\ 1. School of Physics Science, University of Chinese Academy of Sciences, \\ Beijing 100049, China \\ 2. Institute of Porous Flow and Fluid Mechanics, Chinese Academy of Sciences, \\ Langfang, Heibei,065007, China; \\ 3. Research Institute of Petroleum Exploration \& Development-Lang fang, \\ Langfang, Heibei,065007, China \\ 4. SINOPEC Beijing Oil Products Company, BeiJing, China \\ E-mail: gouff@126.com
}

\begin{abstract}
In the binary flooding development process, the viscosity and interfacial tension of binary system are the key to give its play a role of yield increasing effect. Binary system is injected into underground from ground through oil tube at normal temperature, injection speed and well depth are different, the temperature of binary system is different when achieving the formation, and its viscosity and interfacial tension are different. This paper regards wellbore as one-dimensional tube model, considering the thermal conductivity of oil casing annulus and casing pipe, and oil tube wall, set up the tri-coupling mathematical model of formation heat transfer, fluid flow and fluid heat transfer. Because the oil tube is processed as one-dimensional tube with wall thickness, so the problem of narrow diameter ratio is avoided, through numerical simulation, it is obtained different injection rate and well depth, the temperature distribution of wellbore. Further to obtain the binary system at bottom, and the variation relation of its physical properties over the injection rate and injection temperature.
\end{abstract}

Keywords: Solid heat transfer; Fluid heat transfer; Numerical simulation; Coupling equation; Binary flooding

\section{Introduction}

Binary compound flooding is a new tertiary oil recovery technique [1] after ternary compound flooding. In binary flooding development, and the temperature of the system is the key parameter on its effects when reaching the bottom of the reservoir, therefore the calculation of wellbore temperature distribution is very important. Unreasonable fluid injection parameters will not only increase the heat loss, and cause unnecessary waste, but also increase the damage of wellbore structure, and also likely to damage the surrounding rock formation structure. Therefore, reasonable selection of ground dynamic parameters of injected fluid has crucial influence on oil field exploitation.

In 1962, Ramey[2] proposed the famous Ramey formula, which was used in calculating temperature distribution of fluid in wellbore without considering the influence of formation. Hasan 和 Kabir[3] provided highly accurate approximate solution of ground temperature distribution, which given great convenient for engineering application of wellbore heat transfer theory. Guo Chunqiu clearly given the numerical model of both flow temperature and flow pressure prediction. Xiao Zhanshan [5] established the closed mathematical model of mutual coupling of wellbore, injection layer and surrounding rock in injection development, but in solution, it does not couple the wellbore and formation 
for simultaneous solution, only study the temperature distribution in wellbore and formation simply. Wang Gaofeng [6] considered the influence of work applied by friction on temperature on the basis of previous studies, including the wellbore heat transfer equation of friction term. Cong Sunan[7] studied the variation relation of performance and temperature of binary flooding.

But above-mentioned model is only applicable to calculate a small section of the well profile, not suitable for calculating the wellbore temperature distribution, at the same time, it only consider the water temperature distribution of single set of water. This paper process the wellbore as a one-dimensional model, couples the formation temperature filed and wellbore temperature field, at the same time, considering the nature of well fluid viscosity changes over temperature to establish the mathematical model, to get the temperature distribution of binary chemical agent in wellbore by analysis and solution, thus obtain the performance parameters of its arrival at the targeted layer.

\section{Establishment of Model}

In wellbore heat transfer, firstly interior heat transfer of surrounding rock shall be taken into account, surrounding rock heat transfer conforms to porous medium heat transfer equation; secondly, the flow heat transfer of fluid heat transfer shall be considered. Finally, to establish the direct connection of solid heat transfer of tube fluid and surrounding rock, that is tube wall heat transfer, the oil tube wall, oil casing annular and casing wall as the three-layer wall of oil tube, while the inner wall surface is fluid heat transfer, and outer wall surface is solid heat transfer.

\subsection{Model Assumption}

The purpose of this paper is to study the temperature distribution of fluid in wellbore during the injection process, and then the viscosity and interfacial tension properties of the binary system to formation. Due to the depth of the wellbore is much greater than its diameter, so the flow of the fluid in the pipe can be regarded as one-dimensional flow, the axial flow only. At the same time, in order to simplify the problem, only consider plumb wellbore. The volume of wellbore size accounted the surrounding rock can be ignored, so the formation gradient of distance surrounding rock can be assumed not to be affected by wellbore. In addition, due to the wellbore diameter is small, the compressibility of water is small, so the fluid can be assumed as incompressible, and the change of flow on the axial direction can be ignored, in conclusion, the basic assumptions of the model as follows:

(1) The fluid in oil tube flows along axial direction;

(2) The temperature of distance formation conforms to the changes of geothermal gradient;

(3) The wellbore direction is vertical;

(4) The wellbore diameter is not change over well depth;

(5) Fluid is incompressible;

(6) The steady state flow, porosity and density do not change over time;

(7) The fluid in the hole of surrounding rock is water, and does not flow.

\subsection{Mathematical Model}

There are four parts included in the wellbore heat transfer calculation model of injection Well established in this paper: one is the pipe flow model of fluid in the pipe; second is the heat transfer model in the process of fluid flow; third is pipe wall heat transfer model of oil pipe, oil casing annulus and casing pipe; fourth is the solid heat transfer model of wall rocks. The coupling of four models constitutes the mathematical model of this study. 


\subsubsection{Fluid Heat Transfer}

The equation of steady pipe flow heat transfer[8] is

$$
\rho A C_{p} \boldsymbol{u} \nabla T=\nabla \cdot(A k \nabla T)+\frac{1}{2} f_{D} \frac{\rho A}{d_{h}}|\boldsymbol{u}|^{3}+Q_{\text {well }}
$$

In the above formula, $\boldsymbol{u}$ is fluid flow velocity, $\rho$ is fluid density, $A$ is the overflowing interfacial area, $C_{p}$ is the specific heat capacity at constant pressure of fluid in the pipe, $T$ the fluid temperature in the pipe, $k$ is heat conductivity coefficient, $f_{D}$ is Darcy friction factor, $d_{h}$ is the average hydraulic diameter, $Q_{\text {well }}$ is the heat source of wall.

The calculation formula of average hydraulic diameter is

Where, $Z$ represents wetted perimeter.

$$
d_{h}=\frac{4 A}{Z}
$$

For the circular tube studied in this pater, we have

$$
\begin{aligned}
Z & =\pi d \\
A & =\frac{\pi d^{2}}{4}
\end{aligned}
$$

Where, $d$ is the diameter of oil pipe, and $d_{h}=d$.

Darcy friction factor is the function of Reynolds number $(R e)$, pipe roughness $(e)$ and hydrodynamic diameter $\left(d_{h}\right)$, that is

Where,

$$
f_{D}=f_{D}\left(R e, \frac{e}{d_{h}}\right)
$$

$$
R e=\frac{\rho u d_{h}}{\mu}
$$

According to the oil field water injection of $100 \mathrm{~m} 3$ per day, oil pipe diameter of $50 \mathrm{~mm}$ for calculation, Reynolds number is 57.87 , so it belongs to laminar flow. At the same time, the polymer is contained in binary flooding chemical agent, belongs to the nonNewtonian fluid, its rheological property conforms to the power law model

$$
\mu=m(\dot{\gamma})^{n-1}
$$

Where, $\dot{\gamma}$ represents shearing rate, $m, n$ are parameters.

Darcy friction factor of laminar flow, non-Newtonian power law fluid can be calculated by Stokes equation[9].

$$
f_{D}=\frac{64}{R e_{M R}}
$$

Where, $R e_{M R}$ is Metzner modified Reynolds number [10]

$$
R e_{M R}=\frac{\rho u^{2-n} d_{h}^{n}}{8^{n-1} m\left(\frac{3 n+1}{4 n}\right)^{n}}
$$

\subsubsection{Surrounding Rock Heat Transfer}

Surrounding rocks of formation are porous medium, including rocks and fluid in rock, its steady state heat transfer process can be described in heat transfer equation of general solid [11]

$$
\rho^{r} C_{p}^{r} \boldsymbol{u}^{r} \nabla T_{r}=\nabla \cdot\left(k_{e f f} \nabla T_{r}\right)+Q_{r}
$$

In above equation, $\boldsymbol{u}^{\mathrm{r}}$ is the flow velocity fluid in gaps, $\rho^{r}$ is fluid density in the rock, $C_{p}^{r}$ is the specific heat capacity of fluid in rock, $T_{r}$ is the temperature of surrounding rock , $k_{e f f}$ is the effective thermal conductivity of porous medium, can be expressed by weighted sum of heat conductivity coefficient of fluid and rock, $Q_{r}$ is the source item.

$$
k_{e f f}=\theta k_{r}+(1-\theta) k_{l}
$$

In above equation $k_{r}$ represents the heat conductivity coefficient of surrounding rock, $k_{l}$ 表示 represents the heat conductivity coefficient of fluid in the rock, $\theta$ is the volume fraction of surrounding rock.

It can be known form model assumptions that 


$$
\begin{aligned}
& \boldsymbol{u}^{\boldsymbol{r}}=\mathbf{0} \\
& Q_{r}=0
\end{aligned}
$$

Then its heat transfer equation can be simplified to

$$
\nabla \cdot\left(k_{e f f} \nabla T_{r}\right)=0
$$

\subsubsection{Wall Heat Transfer}

It can use Newton's law of cooling to calculate the heat energy density from the surrounding rock to wellbore [11]

$$
Q_{w e l l}=(h Z)_{e f f}\left(T_{r}-T\right)
$$

In above equation, $h$ is heat conductivity coefficient of wall, $\mathrm{Z}$ is the thickness of wall, $(h Z)_{e f f}$ represents the effective value of product of heat conductivity coefficient and thickness of wall.

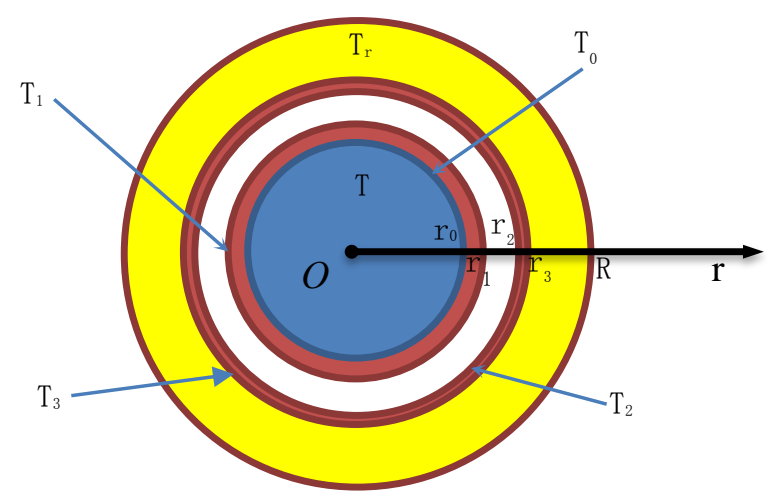

Figure 1. Cross-sectional View of Well Heat Transfer

As shown in Fig. 1, $0 \rightarrow r_{0}$ of the radius range is the fluid of oil pipe, its temperature is $T ; r_{0} \rightarrow r_{1}$ is oil pipe wall, thickness is $\Delta w_{1}$, the temperature of outer wall of oil pipe at $r_{1}$ is $T_{1} ; r_{1} \rightarrow r_{2}$ is the oil casing annulus, thickness is $\Delta w_{2}$, the temperature of outer wall of oil pipe at $r_{2}$ is $T_{2} ; r_{2} \rightarrow r_{3}$ is the casing wall, thickness $\Delta w_{3}$, the temperature of outer wall of oil pipe at $r_{3}$ is $T_{3} ; r_{3} \rightarrow R$ is surrounding rock, temperature is $T_{r}$.

The heat transfer coefficient of fluid in pipe is written as $h_{l}$, the heat transfer coefficient of surrounding rock is written as $h_{r}$, the heat transfer coefficient of oil pipe is $k_{1}$, the heat transfer coefficient of oil casing annulus is $k_{2}$, the heat transfer coefficient of casing is $k_{3}$. Taking a small section at axial direction $\Delta L$, then the heat of fluid in the pipe flowing into inner wall of oil pipe is

By transformation to get

$$
Q=2 \pi r_{0} \Delta L h_{l}\left(T-T_{0}\right)
$$

$$
T-T_{0}=\frac{Q}{2 \pi r_{0} \Delta L h_{l}}
$$

The heat then transfers from the inner wall of oil pipe to outer wall $\left(r_{0} \rightarrow r_{1}\right)$, according to Fourier heat transfer law [11] we have

$$
Q=2 \pi r \Delta L \cdot\left(-k_{1} \frac{d T}{d r}\right)
$$

Separate variables to the above equation, integrate $r_{0}$ to $r_{1}$

By integrating to get

$$
\int_{T_{0}}^{T_{1}} d T=-\int_{r_{0}}^{r_{1}} \frac{Q}{2 \pi k_{1} \Delta L} \cdot \frac{1}{r} d r
$$

$$
T_{0}-T_{1}=\frac{Q}{2 \pi k_{1} \Delta L} \ln \frac{r_{1}}{r_{0}}
$$

In the similar way, we can get the transfer equation of heat in oil casing annulus $\left(r_{1} \rightarrow r_{2}\right)$ and in casing wall $\left(r_{2} \rightarrow r_{3}\right)$. 


$$
\begin{aligned}
& T_{1}-T_{2}=\frac{Q}{2 \pi k_{2} \Delta L} \ln \frac{r_{2}}{r_{1}} \\
& T_{2}-T_{3}=\frac{Q}{2 \pi k_{3} \Delta L} \ln \frac{r_{3}}{r_{2}}
\end{aligned}
$$

The heat transfer equation of outer wall of casing to the surrounding rock and the heat transfer of fluid in the pipe to inner wall of oil pipe, that is

$$
Q=2 \pi r_{3} \Delta L h_{r}\left(T_{3}-T_{r}\right)
$$

By transformation to get

$$
T_{3}-T_{r}=\frac{Q}{2 \pi r_{3} \Delta L h_{r}}
$$

$\operatorname{Add}(20)(21)$, and written as $\Theta=2 \pi \Delta L$, we can get

$$
T-T_{r}=Q\left(\frac{1}{r_{0} h_{l} \Theta}+\frac{\ln \frac{r_{1}}{r_{0}}}{k_{1} \Theta}+\frac{\ln \frac{r_{2}}{r_{1}}}{k_{2} \Theta}+\frac{\ln \frac{r_{3}}{r_{2}}}{k_{3} \Theta}+\frac{1}{r_{3} h_{r} \Theta}\right)
$$

Change to another point of view, considering the heat transferred from the fluid in the oil pipe to the surrounding rock, then

Compared with (24)(25), we have

$$
T-T_{r}=\frac{Q}{\left(h A_{Q}\right)_{e f f}}
$$

Let

$$
\left(h A_{Q}\right)_{e f f}=\frac{1}{\frac{1}{r_{0} h_{l} \Theta}+\frac{r_{1}}{k_{0} \Theta}+\frac{r_{2}}{k_{1}}+\frac{r_{3}}{k_{2} \Theta}+\frac{r_{3}}{k_{3} \Theta}+\frac{1}{r_{3} h_{r} \Theta}}
$$

Then we get

$$
\left(h A_{Q}\right)_{e f f}=(h Z)_{e f f} \Delta L
$$

$$
(h Z)_{e f f}=\frac{2 \pi}{\frac{1}{r_{0} h_{l}}+\frac{r_{1}}{r_{0}}+\frac{r_{2}}{k_{1}}+\frac{r_{1}}{k_{2}}+\frac{r_{3}}{r_{2}}+\frac{1}{k_{3}}+\frac{1}{r_{3} h_{r}}}
$$

To substitute $(h Z)_{e f f}$ into(14), then we can get the heat density $Q_{\text {well }}$ from surrounding rock to wellbore.

\subsubsection{Physical Parameter}

In the heat transfer process of oil well, due to the temperature changes at axial direction and radial direction, the relevant physical parameter of temperature is also changing accordingly. Including heat conductivity coefficient $k$, fluid density $\rho$, atmospheric heat capacity $C p$. The most important two indicators in binary flooding chemical agent are viscosity of chemical agent $\mu$ and its surface tension with oil $\sigma$. Under the condition of other parameters determined, the two are the function of temperature, its relationship can be measured by experiment. In conclusion, the relationship between physical parameters and temperature is

$$
\left\{\begin{aligned}
k & =k(T) \\
\mu & =\mu(T) \\
\rho & =\rho(T) \\
C p & =C p(T) \\
\sigma & =\sigma(T)
\end{aligned}\right.
$$

After determining the temperature distribution of fluid in the oil pipe, one can calculate the viscosity of the fluid and its surface tension with oil.

\section{Model Solution}

Figure 2 is sketch of geometry model and grid, due to the axisymmetric characteristics, the original three-dimensional problem can be reduced to a two-dimensional axisymmetric under elliptic coordinate problem for solving. 


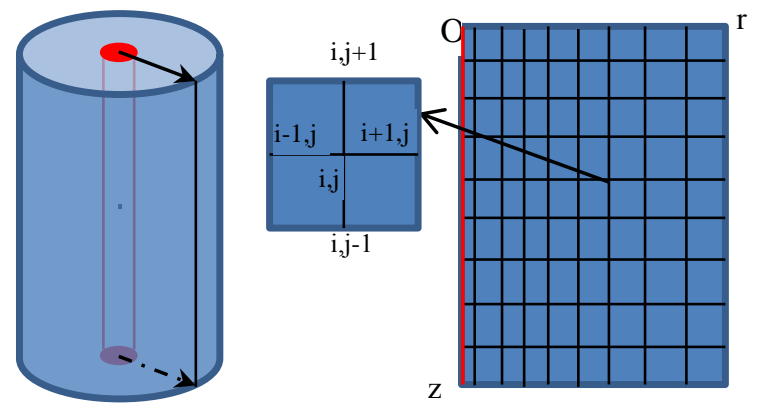

Figure 2. Sketch of Geometry Model and Grid

\subsection{Pipe Flow Model Solution}

The expansion equation of equation (1) on one-dimensional z-axis is

$$
\rho A C_{p} u \frac{\partial T}{\partial z}=A k \frac{\partial^{2} T}{\partial z^{2}}+\frac{1}{2} f_{D} \frac{\rho A}{d_{h}} u^{3}+Q_{w e l l}
$$

Wellhead temperature is ground temperature $T_{s c}$, and wellbore bottom is the boundary of heat flow. And its corresponding boundary condition is

Where, $T_{s c}$ represents ground temperature.

$$
\left\{\begin{array}{l}
\left.T\right|_{z=0}=T_{S c} \\
\left.\frac{\partial T}{\partial z}\right|_{z=H}=0
\end{array}\right.
$$

Combined with the boundary condition to solve the above formula, and get the temperature distribution of fluid in well $T$.

\subsection{Temperature Field of Surrounding Rock Solution}

Temperature field of surrounding rock around the $\mathrm{z}$ axial symmetry, so the equation (5) under cylindrical coordinate system to be expanded as

$$
\frac{\partial}{\partial r}\left(r k_{e f f} \frac{\partial T_{r}}{\partial r}\right)+\frac{\partial T_{r}}{\partial z}=0
$$

The temperature of the surrounding rock is the ground temperature $T_{s c}$, temperature at distance position of radial direction $r$ increases according to formation temperature gradient $a$, the surrounding rock of well bottom is the boundary of heat flow. Then the boundary condition of heat transfer in surrounding rock is:

$$
\left\{\begin{array}{c}
\left.T_{r}\right|_{z=0}=T_{s c} \\
\left.\frac{\partial T_{r}}{\partial z}\right|_{z=H}=0 \\
\left.T_{r}\right|_{r=\infty}=T_{s c}+a z
\end{array}\right.
$$

Combined with the boundary condition to solve the above formula, and get the temperature distribution of fluid in well $T_{r}$.

\subsection{Solving Steps of Two Fields Coupling}

This model involves the temperature field in oil pipe $T$ and temperature field in surrounding rock $T_{r}$, two fields are coupled together at interface due to heat transfer $Q_{\text {well }}$. At the same time, other physical parameters are function of temperature. To solve the above mathematical equation, it needs iteration solving of two fields simultaneous.

(1) Suppose the wall heat transfer is $Q_{\text {wall }}^{*}$ at nth step iteration;

(2) according to equation (30) and (32) to solve the fluid temperature field of oil pipe is $T^{n}$, and temperature field of surrounding rock is $T_{r}^{n}$;

(3) update the physical property parameter according to equation (29);

(4) To solve $Q_{\text {wall }}^{n+1}$ according to equation (14). 
(5) To determine err $=\left\|Q_{\text {wall }}^{n+1}-Q_{w a l l}^{*}\right\|, \quad$ if the err is small enough to satisfy accuracy $\varepsilon$, then the solution is regarded as convergence, and stop iteration, otherwise, let $Q_{\text {wall }}^{*}=Q_{\text {wall }}^{n+1}$. And repeat the processes(2) (4), until the solution is convergence.

\section{Simulation Examples}

This paper simulates the fluid temperature changes of well during the injection process of binary chemical agent at well depth of $3000 \mathrm{~m}$, and according to the changes of temperature to calculate the changes of fluid viscosity and surface tension.

\subsection{Physical Property Parameter Value}

The parameter value list as follows:

Table 1. Parameters of Simulation

\begin{tabular}{cc}
\hline Name & Value \\
\hline Well depth $\mathrm{H}(\mathrm{m})$ & 3000 \\
Ground temperature $\mathrm{T}_{\mathrm{sc}}(\mathrm{K})$ & 293 \\
Formation proposity $\theta$ & 0.2 \\
Geothermal gradient a $(\mathrm{K} / \mathrm{m})$ & 0.03 \\
injection rate $\mathrm{q}(\mathrm{m} 3 / \mathrm{d}) \mathrm{Water}$ & 40 \\
diameter of oil pipe $(\mathrm{mm})$ Outer & $101.6(4 \mathrm{in})$ \\
diameter of oil pipe $(\mathrm{mm})$ Inner & $88.3(4 \mathrm{in})$ \\
diameter of casing $(\mathrm{mm})$ Outer & $127(5 \mathrm{in})$ \\
diameter of casing $(\mathrm{mm}) \mathrm{Inner}$ & $115.8(5 \mathrm{in})$ \\
The air heat conductivity $\mathrm{k} 1(\mathrm{~W} / \mathrm{m} \cdot \mathrm{k})$ & 0.023 \\
The heat conductivity of pipe wall $\mathrm{k} 2(\mathrm{~W} / \mathrm{m} \cdot \mathrm{k})$ & 50.2 \\
The heat conductivity of casing wall $\mathrm{k} 3(\mathrm{~W} / \mathrm{m} \cdot \mathrm{k})$ & 50.2 \\
Gravitational acceleration $\mathrm{g}(\mathrm{m} / \mathrm{s} 2)$ & 9.8 \\
Specific heat capacity of fluid $\gamma$ & 1 \\
\hline
\end{tabular}

The values of density of fluid binary system $\rho$, heat conductivity coefficient $k$ and atmospheric heat capacity $C p$ are taken according to the parameters of water[13] under standard condition, the curve of binary system viscosity and interfacial tension changing over temperature as follows [14] : 

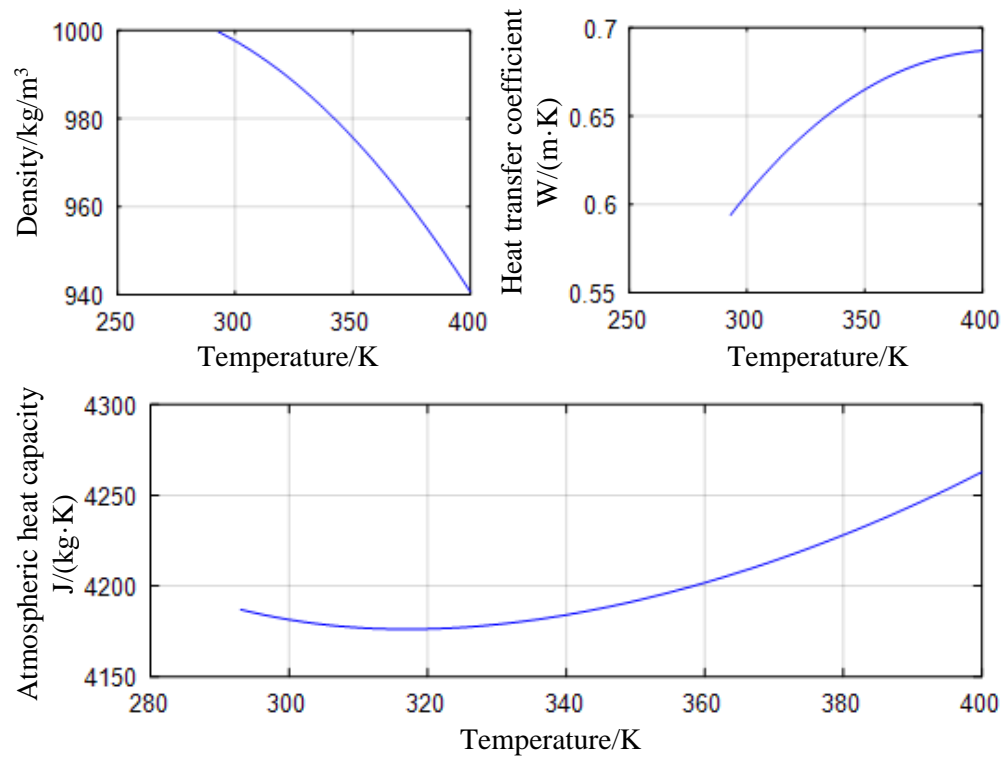

Figure 3. Curve of Physical Property Parameter of Polymer/surfactant Flood Changes with Temperature

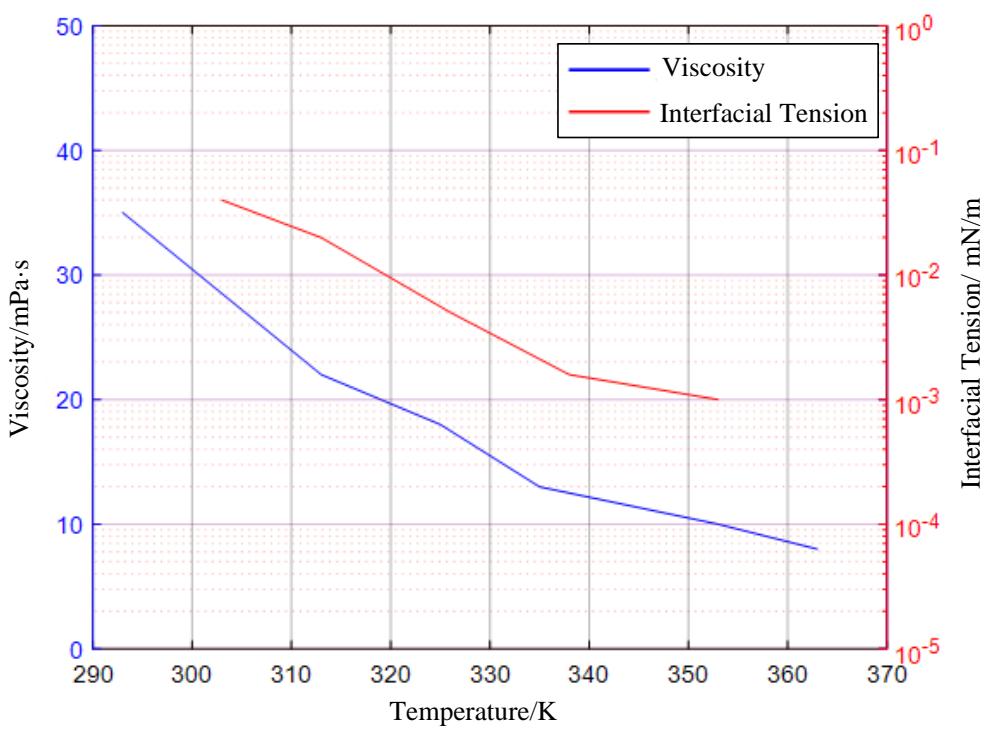

Figure 4. Curve of Polymer/surfactant Flood Viscosity and Interfacial Tension Changes with Temperature

As shown in Fig.4, when the binary flooding fluid under the condition of laboratory, the viscosity achieves $35 \mathrm{mPa} \cdot \mathrm{s}$ at room temperature, when the temperature rises to $360 \mathrm{~K}$, the viscosity declines to $8 \mathrm{mPa} \cdot \mathrm{s}$; the oil-water interfacial tension of binary flooding fluid shows exponential decrease as the increase of temperature,.

\subsection{Solution Results}

According to the above models and parameters, it compiled MATLAB program to solve and get the result of wellbore temperature and formation temperature change over the well depth, and then get the fluid viscosity and interfacial tension change over the well depth. 


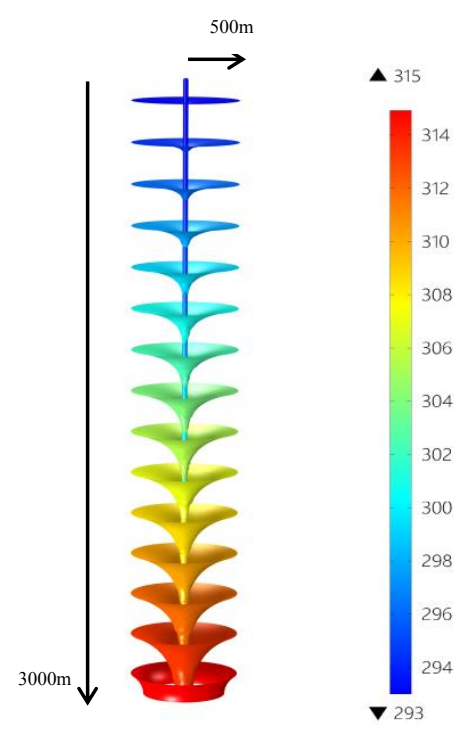

Figure 5. Contour Map of Temperature of Fluid in Wellbore and Formation

Figure 5 is the temperature contour map of the whole solution area, temperature increases with well depth at longitudinal direction, and the temperature shows funnelshaped distribution at the horizontal direction.

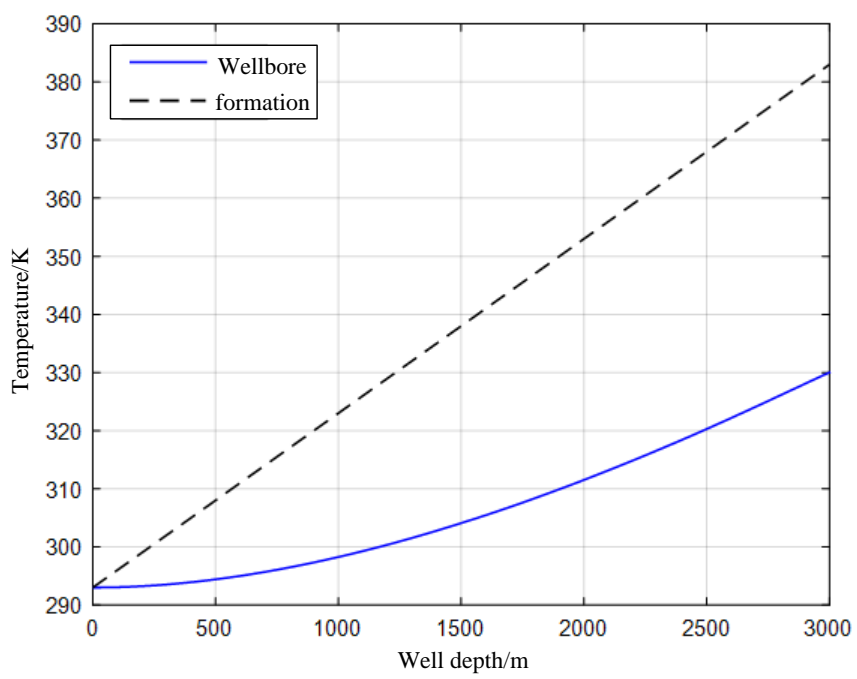

Figure 6. Curve of Temperature of Fluid in Wellbore and Formation

Figure 6 is the comparison of temperature of fluid in wellbore and formation, along with well depth, the formation temperature rises at $3 \mathrm{~K} / \mathrm{m}$ gradient; the temperature of fluid in wellbore is significantly lower than the formation temperature. 


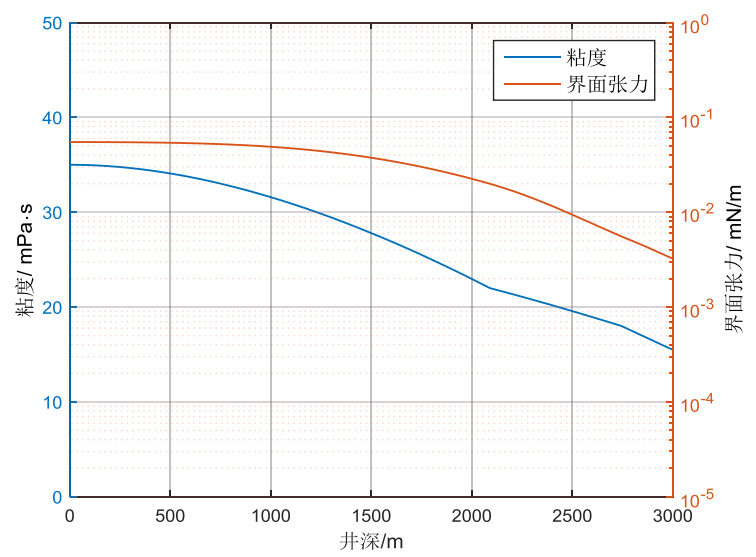

Figure 7. Curve of Polymer/surfactant Flood Viscosity and Interfacial Tension Changes with Depth of Well

Figure 7 is the comparison of temperature of fluid in wellbore and formation, along with the increase of well depth, the formation temperature rises at $3 \mathrm{~K} / \mathrm{m}$ gradient; the temperature of fluid in wellbore is significantly lower than the formation temperature.

\section{Parameters Influence Analysis}

Different Wells and blocks, the injection rate of binary flooding site and the adopted pipe size are different, so the influence of temperature, viscosity, and oil-water interfacial tension of binary flooding fluid in the wellbore are also different.

\subsection{The Effect of Injection Rate}

Other parameters are maintained the same as above, take $q=10,20,40,80\left(\mathrm{~m}^{3} / \mathrm{d}\right)$ respectively, the results of numerical simulation as shown in figure 8 .

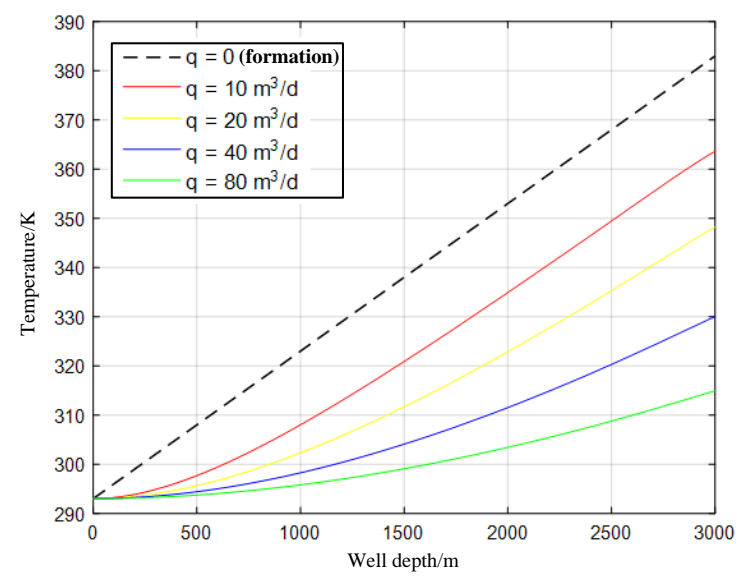

Figure 8. Curve of Flood Temperature Changes with Depth of Well at Different Quantity of Flow in Wellbore

It can be seen from the figure 8 , in the case of other parameters different, the greater of injection well flow rate is the temperature of fluid in wellbore is lower. From the theoretical analysis, this is because the greater of the flow, the shorter the time of fluid arrived the bottom, the less of the absorbing heat, so the temperature is lower.

To calculate well depth at $3000 \mathrm{~m}$, under different flow, fluid viscosity and interfacial tension, as shown in figure 9. 


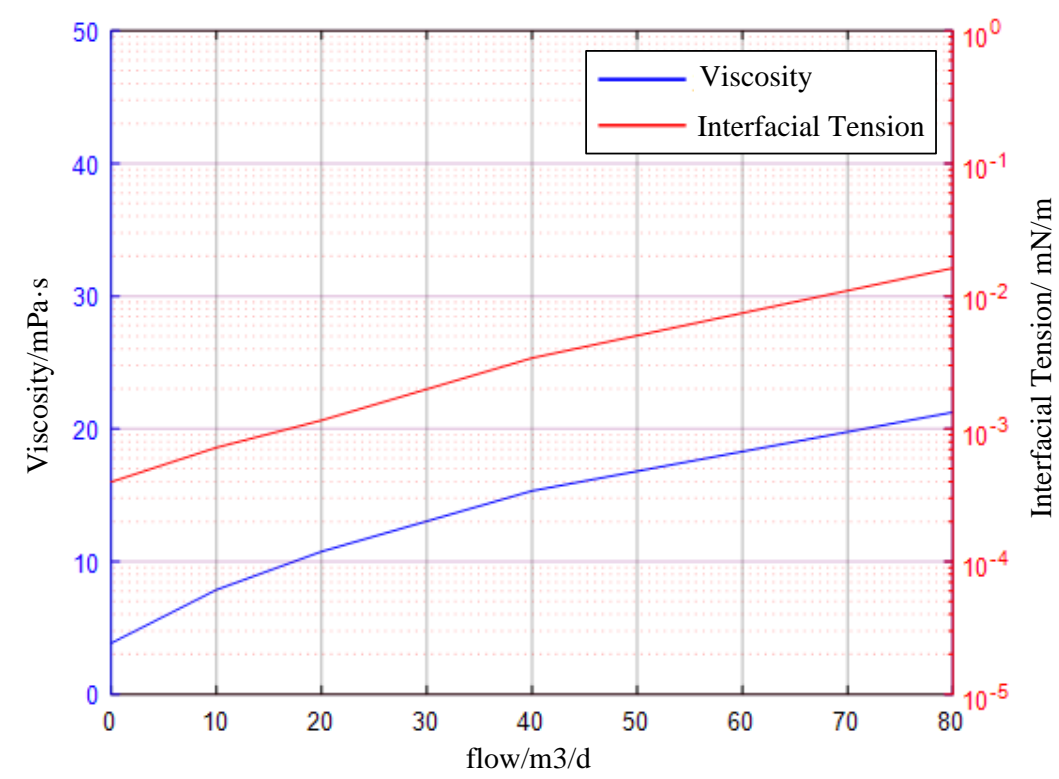

\section{Figure 9. Curve of Polymer/surfactant Flood Viscosity and Interfacial Tension Changes with Quantity of Flow}

Figure 9 shows that with the increase of injection rate, at the same well depth, both the viscosity and oil-water interfacial tension of binary system are increased, this is because the lower of the temperature, the viscosity is greater and interfacial tension is larger. The increase of the viscosity is helpful for the displacement of reservoir oil, but the increase of the interfacial tension is unfavorable to the displacement of reservoir oil.

\subsection{The Influence of Pipe Inner Diameter}

Other parameters are maintained the same as above, calculate the influence of different pipe sizes (1.9 ", 2-7/8", 3-1/2", 4") to the result. Different pipe sizes, the inner diameter, wall thickness, and outer diameter are different, to distinguish pipe sizes with inner diameter, the numerical simulation of concentration of chemical agent at outlet is shown in figure 10. 


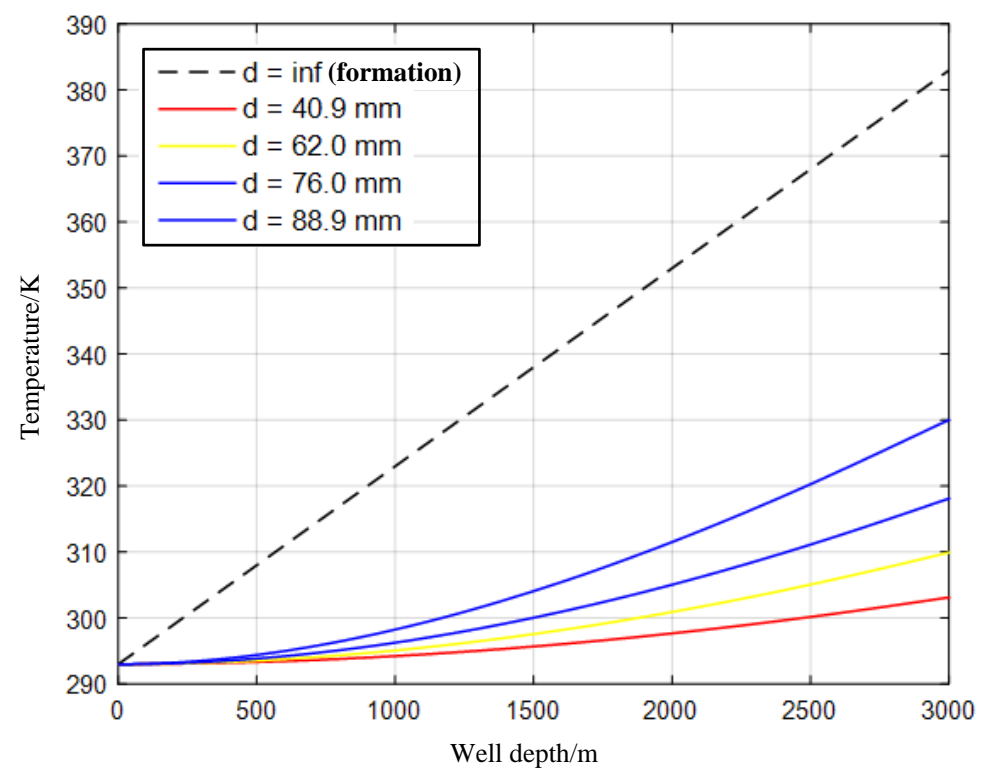

Figure 10. Curve of Flood Temperature Changes with Depth of Well at Different Size of Pipe in Wellbore

To analyze figure 10, the greater of the inner diameter of pipe, the temperature of fluid in wellbore at the same well depth is higher. This is because under the same flow rate, the greater of inner diameer of pipe, the smaller of flow velocity it is, the longer time of fluid arrived the bottom, the more of the absorbing heat, so the temperature is higher.

the time of arrival in bottom hole is the more absorption of heat, so the higher temperature.

To calculate the depth of $3000 \mathrm{~m}$, under different inner diameter of pipe, fluid viscosity and interfacial tension, as shown in figure 11.

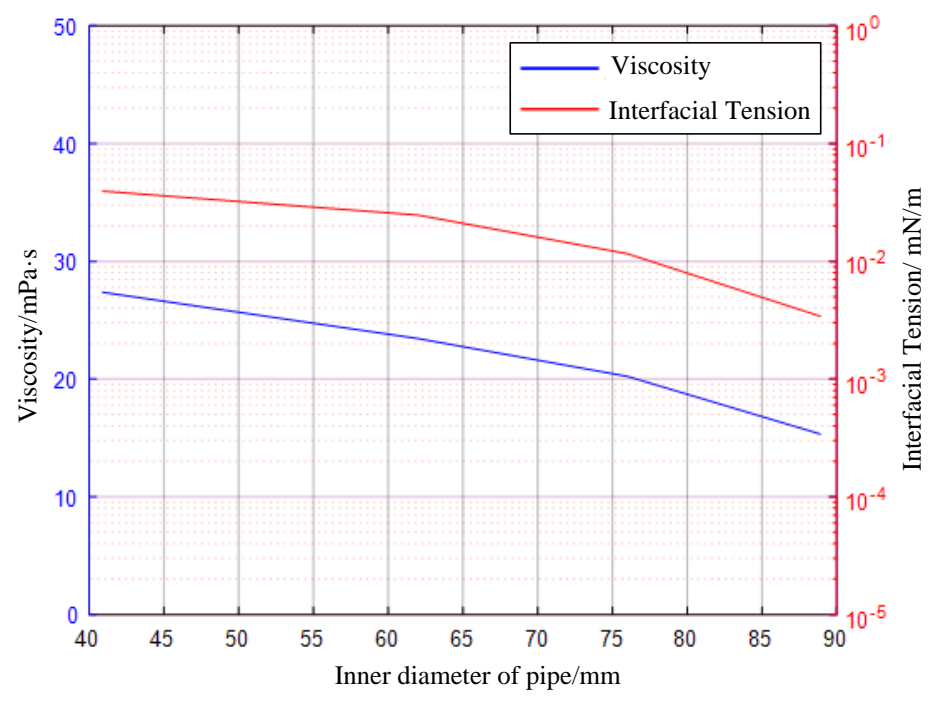

Figure 11. Curve of Polymer/surfactant Flood Viscosity and Interfacial Tension Changes with Size of Pipe

Figure 11 shows that with the increase of inner diameter of pipe, at the same well depth, both the viscosity and oil-water interfacial tension of binary system are decreased, this is because the higher of the temperature is, the viscosity is lower and interfacial 
tension is smaller. The decrease of the viscosity is unfavorable for the displacement of reservoir oil, but the decrease of the interfacial tension is helpful to the displacement of reservoir oil.

\section{Conclusion}

Based on the heat transfer model of one-dimensional fluid and formation, in the process of binary flooding calculation, the temperature change of fluid in the wellbore, the influence of different injection rate and pipe size on its viscosity and oil-water interfacial tension is analyzed, we get the following conclusion.

(1)At the same depth, the temperature of fluid in wellbore is obviously lower than the temperature of formation, and shows funnel-shaped distribution;

(2)The main factor to determine the temperature of fluid in wellbore is its flow rate. Whether increasing the flow rate, or decrease the size of pipe, are actually increase the injection rate, so as to decrease the temperature of fluid in wellbore at the same well depth;

(3)The greater of viscosity of polymer in binary flooding is helpful to displacement of reservoir oil within a certain scope, which requires the lower of the temperature of fluid to the formation is better; the surfactants reduce oil-water interfacial tension, the lower of the tension is more favorable for displacement of reservoir oil, this requires the higher of the temperature of fluid to the formation is better for displacement of reservoir oil. Both are contradicted, one should compressively analyze and consider the effect of temperature on the displacement of reservoir oil to both, and choose the injection flow rate and pipe size reasonably, in order to get optimal displacement of reservoir oil.

\section{Acknowledgement}

The National Foundation of China under Grant No. 51174170

\section{References}

[1] Lv Xin, zhang Jian, Jiang Wei. Binary compound flooding research progress of polymer/surfactant[J]. Journal of southwest petroleum university (natural science edition), (2008),03:127-130.

[2] Ramey H J. Well bore heat transmission [J] . JPT ( April 1962) , 427 435.

[3] Hasan A R, Kabir C S. Aspects of wellbore heat transferduring two-phase flow(includes associated papers 30226and 30970)[C]. SPE 22948, (1994).

[4] Guo Chunqiu, Li Yingchuan. Comprehensive numerical simulation of gas well pressure temperature prediction [J]. Journal of oil, (2001),22(3):100-104.

[5] Xiao Zhanshan. Numerical simulation of down hole temperature field of injection well [D]. Daqing petroleum institute, (2002).

[6] Wang Gaofeng, Hu Yongle, Li Zhiping, Yuan Wei, Jiao Yuwei. Improvement and application of Ramey wellbore heat transfer equation[J]. Journal of southwest petroleum university (natural science edition), (2011), 05:118-121+198-199.

[7] Cong Sunan, Liu Weidong. Binary compound drive temperature boundary study [J]. Science Technology and Engineering, (2012),32:8687-8689.

[8] Lurie MV. Modeling of Oil Product and Gas Pipeline Transportation [M]. Weinheim: WILEY-VCH Verlag GmbH \& Co KGaA, (2008).

[9] Churchill SW.Friction factor equation spans allfluid-flow regimes[J]. Chem. Eng, (1997), 84(20):91-92..

[10] Metzner AB, Reed JC.Flow of non-Newtonian fluids - correlation of the laminar, transition, and turbulentflowregions[J].AIChE Journal, (1955),1(4):434-440.

[11] Incropera FP,DeWitt DP. Fundamentals of Heat and Mass Transfer[M].Wiley:John Wiley \& Sons, (1996).

[12] Barnard CL. etal. A Theory of Fluid Flow in Compliant Tubes[J]. Biophysical Journal, (1966), 6(6): $717-724$.

[13] Leigh G J, FAVRE H A. Principles of chemical nomenclature: a guide to IUPAC recommendations [M]. UK:Blackwell Science Ltd, (1998)

[14] Cong Sunan, Liu Weidong. Binary compound drive temperature boundary study [J]. Science Technology and Engineering, (2012),32:8687-8689. 


\section{Authors}

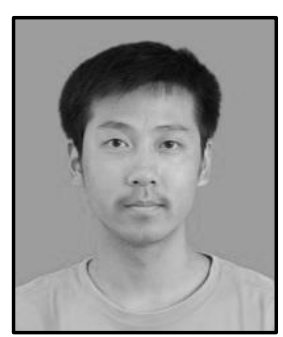

Gou Feifei, He received her B.S. degree in petroleum engineering from China University of Petroleum-Beijing in Beijing, China. He is currently reading a doctorate in the University of Chinese Academy of Science. Her research interest is mainly in the area of percolation fluid mechanics. He has published several research papers in scholarly journals in the above research areas. 